\title{
Analysis of Life Expectancy Rate at Birth in the Republic of Tatarstan
}

\section{Gabdrakhmanov N.K.}

Kazan Federal University, Institute of Management, Economics and Finance, Kazan, 420008, Russia

Rubtzov V.A.

Kazan Federal University, Institute of Management, Economics and Finance, Kazan, 420008, Russia

Mustafin M.R.

Kazan Federal University, Institute of Management, Economics and Finance, Kazan, 420008, Russia

Antonova N.V.

Kazan Federal University, Institute of Language, 420008, Kazan, Russia

\section{Doi:10.5901/mjss.2014.v5n24p272}

\begin{abstract}
The current economic growth rate in the Republic of Tatarstan cannot serve as the only progress and welfare index of the region. This can be due to the fact that the continual economic growth of public welfare caused a number of adverse effects, such as environmental disorder, social strain intensification, etc. that is why it is necessary to reinforce another measure of our further well-being. This article specificates a particular criterion, forming part of the integral "life quality" rate, i.e. the expected life expectancy at birth. To complete this task a profound scientific research at a regional level is required. This article presents results of an analysis of life expectancy rate at birth as a way to evaluate life quality in the Republic of Tatarstan. The research results show that there is a territorial and gender disparity. The authors make this fact conditional on job distinctive features, unhealthy lifestyle, carelessness which leads to disregard one's own health. So, they suggest including this rate as an indicative one while assessing the heads of the Republic of Tatarstan municipal units. This research aims to assess life quality from the perspective of life expectancy at birth. This work presents a monitoring of expected lifespan for the Republic of Tatarstan population as compared to other regions of the Volga Region Federal District. It also considers the situation within the republic at a municipal level. Practical implementation of the recommendations drawn up in the course of the research will promote development of a reasonable regional programme to maintain and improve public welfare. This research is based on traditional methods: cartographical (methodologically founded on subject and complex mapping and advances in geoinformation technologies), comparative and descriptive, spatial analysis method and the statistical one. Processing and analysis of fact sheets was carried out with the help of special geoinformation, cartographic and statistic software.
\end{abstract}

Keywords: life quality, life expectancy at birth.

\section{Introduction}

Nowadays economic growth in the Republic of Tatarstan cannot be the only progress and welfare index of the region. This can be due to the fact that the continual economic growth of public welfare caused a number of adverse effects, such as environmental disorder, social strain intensification, etc. that is why it is necessary to reinforce another measure of our further well-being (эта фраза уже была в аннотации) (Bagautdinova et al., 2013). This statement was supported by Rustam Minnikhanov, the President of the Republic of Tatarstan, during the "United Russia" public primary elections in August, 2011 in Musliumovo, when he declared: "The basic authorities efficiency criterion in Tatarstan is life quality of the population, and it is its improvement that makes the primary goal of the regional authorities". Hence, we can say that life quality is the modern paradigm of civilization development (Fakhrutdinova et al., 2013). This implies a need to find out the relation between life quality elements and new approaches to creation and implementation of life quality evaluation methods. The notion of "population life quality" can be defined as "assessment of the complex of living conditions characteristics, as it arises in public consciousness" (Boitsov B.V. and others, 1997).

Average expected lifespan in the country is largely contingent on social living standards (Gabdrakhmanov, 2011). 
Life expectancy depends on numerous factors, such as: lifestyle (one of the most important ones), income level, upbringing and education, genetic background, environmental contamination, diet quality, healthcare system development level, crime rate, possibility to freely earn one's living and many others (Gabdrakhmanov and Egorov, 2013).

Scientists from various fields of knowledge have long been using the index of expected lifespan or average life expectancy which equals to an arithmetical average of survival distribution up to an $x$-age (the resting length of life) in accordance with the frequency of deaths, as recorded in mortality tables (Kvasha, 1994). The idea of a loss meter based on ill health is comparatively recent, it was suggested by B. Sanders in 1964 (Sanders, 1964). The calculation methodology and the name "Healthy life expectancy" or "Disability free life expectancy" were offered by D. Sullivan in 1971 (Sullivan, 1971).

\section{Methods}

It has long been proved that it is not only socio-economic environment that impacts public health, but public health impacts the national economy to a large extent as well (Safiullin et al., 2013). This influence continually grows and is present in almost all countries. In the recent years socio-economic relations have changed, which resulted in social and economic instability. The latter in its turn had a profound effect on national health, both directly and indirectly. Since the health of the current generation bears the impress of life quality in the past and depends on multiple present day factors, we should use a package approach to its evaluation to get reasonable prospects for the nearest future (Fakhrutdinova et al., 2013).

It is evident both from the literature on the subject and our own research that under relatively stable environmental conditions national health declines: death rate grows as well as functional deviations; infant physical growth rate goes down; there are substantial discrepancies in morbidity rate between children living in the same ecological area but in different living conditions.

Thus we can infer that ecology has a minor effect as compared to social factors, and the main negative impact is exerted by socio-economic environment of the country, related to the process of social reforming.

In accordance with the Federal plan of statistical efforts, due to different time frames of information availability, the "life expectancy at birth (years)" index is presented on a phased basis within the following time periods:

$1^{\text {st }}$ assessment (preliminary) - March, 15;

$2^{\text {nd }}$ assessment (final) - August, 15.

$1^{\text {st }}$ assessment (preliminary) - to be reported before March, 15.

The rate is calculated on the basis of preliminary data on age and gender composition of the deceased (ignoring the final medical evidence), grouped by age, and preliminary assessment of age and gender composition of the population.

The algorithm to get the rate is the following: to calculate future life expectancy we should calculate the number of man-years, which those who have lived up to the given age are expected to live during the whole period of the forthcoming life (up to the given age and up to the maximum age). The received total of man-years is divided by the number of those who lived up to the given age.

$e(x)=\frac{T(x)}{I(x)}$,

Where :

$x-$ is age

$\mathrm{e}(\mathrm{x})$ - is life expectancy;

$\mathrm{T}(\mathrm{x})$ - number of man-years;

$\mathrm{I}(\mathrm{x})$ - number of those who lived up to the given age.

Life expectancy at birth - the index for $x=0$.

The source of information is a preliminary assessment of age and gender composition of the population, the number of the deceased grouped by age, received as a result of the Federal Statistic Efforts N 1-Y "Accounts of death" without including the final medical certificates of death, issued following the results of the forensic medical examination in exchange for the preliminary ones.

The $2^{\text {nd }}$ assessment (final) - to be reported before August, 15.

The index is calculated by the algorithm described above, taking into account the final assessment of the age and gender composition of the population and the detailed age composition of the deceased basing on the final medical certificates of death (Procedure for approving the rate calculation methods for operational evaluation..., 2013). 


\section{Results}

Between 1995 and 2010 death rate in able-bodied population was rather high. Despite a relative decline in 1996-1999 (597.4; 573.7; 538.9 and 557.0 per 100,000), in $2000(613,6$ per 100,000) the mortality rate in able-bodied population increased again and in 2005 it achieved its peak over this period $(671,8$ per 100,000). In the following years, between 2005 and 2009 death rate decreased by $22.5 \%$.

It should be stressed that the leading causes of death in able-bodied population were injuries, intoxication and external factors. However, starting from 2005 the pattern changed and by 2010 circulatory diseases $(63,4 \%)$ became the first leading cause of death, followed by injures and intoxication (10,5\%), the third leading cause of death being tumors $(13,4 \%)$. By contrast, in 1995 injures and intoxication accounted for 39,6\% of deaths, circulatory disease was responsible for $29,5 \%$ and tumors $-12,6 \%$. The mortality rate for males and females was the following:

Injures and intoxication - $41,1 \%$ and $31,8 \%$;

circulatory diseases $-30,1 \%$ and $26,1 \%$ :

malignant tumors $-11,2 \%$ and $20,2 \%$.

In the mortality rate for the Republic of Tatarstan population circulatory diseases is the leading cause of death $(63,4 \%)$, the second leading causes are tumors $(13,4 \%)$ and external factors (accidents, intoxications, injures, etc.) 10,5\%. In 2009 this number surpassed 834 individuals per 100,000, where the deaths by accidental alcohol intoxication over the given period range from 10.67 to 14.9 per 100,000. Rural inhabitants are 1.2-1.9 times more likely to die by these reasons than citizens. In 2009 in the Republic of Tatarstan were recorded 160 deaths by drowning and 137 deaths by alcohol intoxication.

There is a number of factors to account for this phenomenon, which cannot be treated separately. Among the causes of low life span in some of the Republic of Tatarstan municipal areas are smoking, mental and social stress, faulty diet, and especially excessive alcohol consumption. It should be noted that every year tens of thousands of people die by consuming defective alcohol or alcohol-containing medical products not intended for internal use.

The Republic of Tatarstan dominates among other territorial entities of the Volga Region Federal District in life expectancy at birth (Gabdrakhmanov and. Rozhko, 2014). (Fig.1).

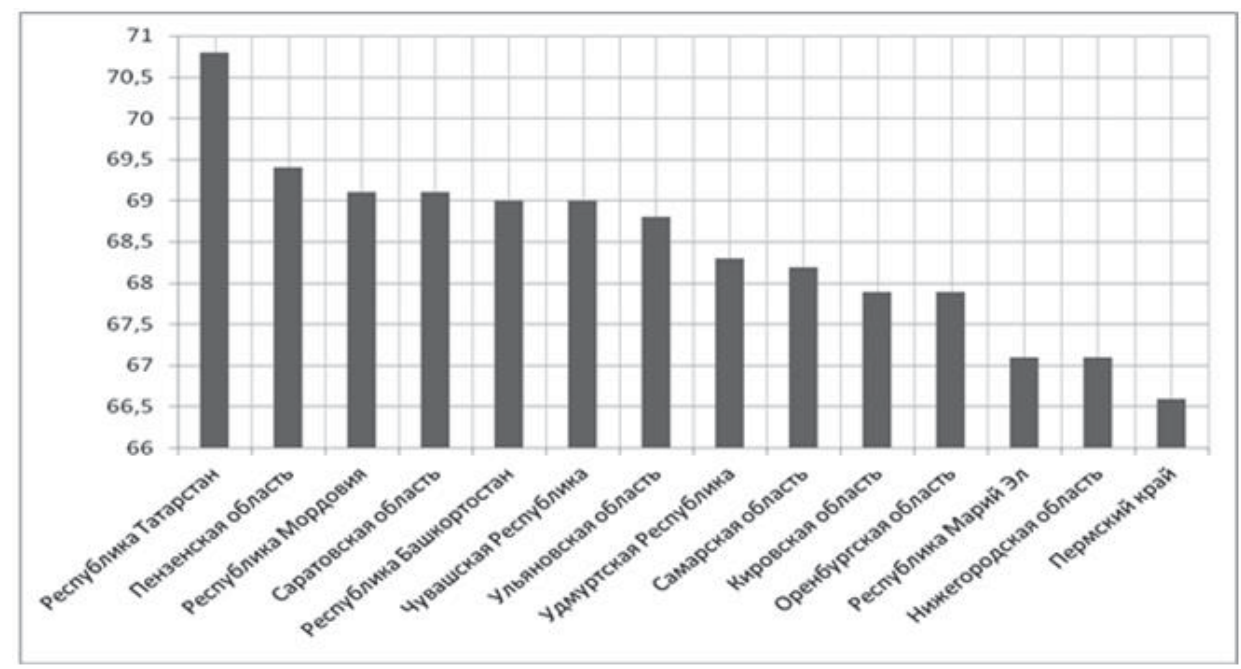

Figure 1. Life expectancy rate in the Volga Region Federal District in 2009.

Therefore an average baby, born in 2009 can expect to live 70.8 years, while in the Perm Territory the expected life span is only 66.6 years. If we analyze this index as it develops between 1990 and 2009 (Fig.2) we can notice a decrease by 4.2 years between 1990 and 1995, followed by a rise up to 1998 when the average life span was 68.9 years; in the next four years the index showed another decline. Starting from 2002 there is a gradual growth in life span and in 2009 it achieved its peak, which is commensurate with 1990 (70.9 years). Analyzing life expectancy at birth we can observe an undulate tendency with the minimum value between 1994 and 1995 (66.7 years), and 2001 and 2002 (67.5) and the maximum value in 1990 and 2009 (70.9 and 70.8 accordingly). 


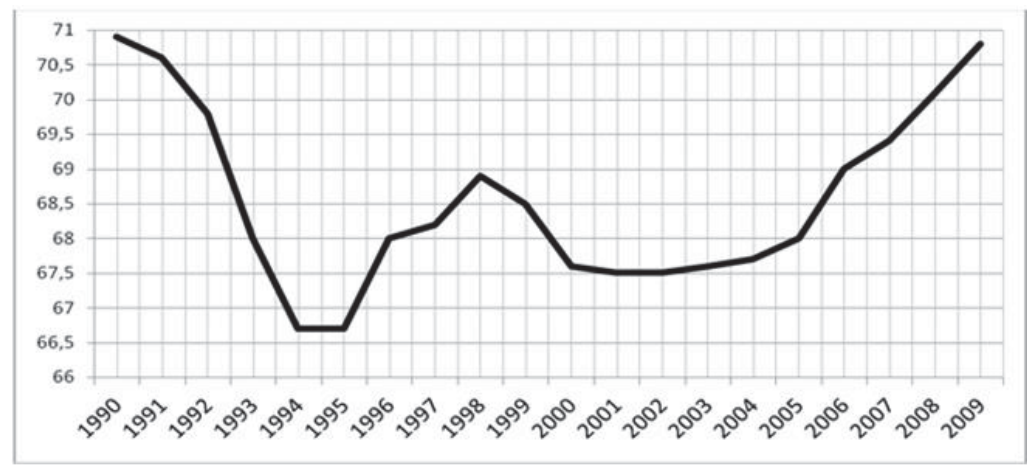

Figure 2. Trends in life expectancy rate at birth in the Republic of Tatarstan.

A specific feature which characterizes the present situation in the Russian Federation is a huge difference in life expectancy at birth between men and women. In highly developed European countries as well as in Muslim countries with an extensive healthcare network the difference in life span between men and women is 3 - 5 years. The majority of Russian women have an assured 12 years difference in life span. In 2009 this difference was 11.62 years which just confirms the all-Russia index. This rating is irregularly distributed in space, for example districts with the maximum disparity are located in the western regions of the republic while those with the minimum disparity are to the east (map chart 2). The minimum disparity in life span between men and women in 2009 , which is commensurate with the European rating, was recorded in the Mamadysh district (3.58 years). The maximum disparity was reported by the Cheremshansky district (17.49 years).

Another point to be noted is life expectancy in urban and rural areas (Fig. 3). In the cities men are expected to live longer than in the country. Among females the situation is quite different, that is women live longer in the countryside than in the cities. This is primarily due to the lifestyle and social habits which result in heavy mortality (death rate for working age people is high especially among males).

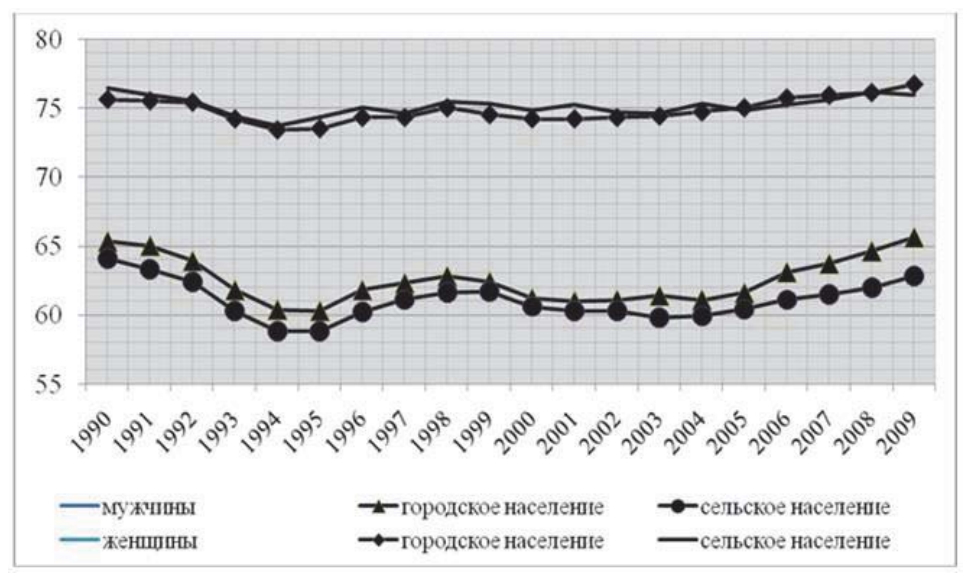

Figure 3. Variations in male and female life expectamcy at birth beween urban and rural areas.

\section{Discussion}

It stands to reason that life expectancy rate at birth is included into the check list to assess the Republic of Tatarstan Ministry of Healthcare performance. In order to control the implementation of the agreement with the municipal units this rate is included as an indicative to rank the municipal healthcare providers. In view of relevance and importance of life expectancy rate at birth and its relation to social factors, as well as lack of motivation to lead a healthy life among the population of the republic, we consider it expedient to include this index as an indicative while assessing the heads of the Republic of Tatarstan municipal units. 


\section{Inference}

Analyzing working age male mortality rate by place of residence (urban or rural area) it is necessary to note that this rate is 1.3 times higher in the countryside than in the city. At the same time, male mortality is 3.9 times higher than female mortality in the city, while in the rural area this rate equals to 4.4 times.

While for working age urban males death rate by all diseases went down, there is a growth in death by cancer among rural working age population (by $13.9 \%$ ).

Death rate by injures, intoxication and some other external factors is 5.1 times higher for men than for women in the city and 5.6 in the countryside; circulatory diseases -5.1 and 5.4, and tumors -1.9 and 2.3 accordingly.

At that, working age population death pattern is approximately the same in both communities, the leading causes of death being circulatory diseases, injures, intoxication, external factors and tumors.

Death rate among working age females by the place of residence (urban or rural area) shows almost the same tendency. Both in the cities and in the countryside the most common cause of death is circulatory disease, the second leading causes are injures and intoxication, the third major cause is tumor.

The present public health crisis in Russia is driven not only by the "old" causes of death, such as communicable diseases, but also by "new" types of disorders, circulatory diseases being the major one. Social problems lead to convergence of endogenous and exogenous causes of death (Panasyuk et al, 2013).

Other social and psychological risk factors are: low level of social and behavioral culture, lack of motivation to lead a healthy life in popular mentality, low public awareness.

\section{Conclusion}

Analyzing the trends in life expectancy rate at birth we have found the following. The minimum rate in 2009 was reported in Pestrechinsky district (59,765 years), and the maximum was is Leniogorsk (80,385 years). The majority of municipal areas, except Pestrechinsky, Atninsky, Mendeleevsky, Muslumovsky, Nizhnekamsky, Spassky, Cheremshansky, Baltasinsky, Kaibitsky and Kamsk-Ustinsky, reported an increase in life expectancy between 2007 and 2009. Taking into consideration space factor we can notice that the last on this list are the western areas of the republic, where the rate is below average. In the Eastern areas of the republic the present situation is more favorable. Another point to be noted is low rate of life expectancy at birth in the areas located on the Kama and Volga rivers.

\section{References}

Andreev, Evgueni M., Martin McKee, and Vladimir M. Shkolnikov. "Health expectancy in the Russian Federation: a new perspective on the health divide in Europe." Bulletin of the World Health Organization 81.11 (2003): pp.778-787.

Andrews, Frank M., and Stephen Bassett Withey. "Social indicators of well-being: Americans' perceptions of life quality." (1976): pp.1935.

Bagautdinova, N.G., Panasyuk, M.V., Gafurov, I.R. Wavelet analysis of the territorial socio-economic system dynamics // World Applied Sciences Journal, 27(13), 2013, pp. 62-66.

Fakhrutdinova, E., Karasik, E., Safina, L., Miropol'skaya, N. The role of social protection in formation of quality of work life// World Applied Sciences Journal.Volume 27, Issue 13, 2013, pp. 72-76.

Fakhrutdinova, E., Safina, L., Kolesnikova, J., Fedor, Mikhailov. Quality formation of working life of the youth// World Applied Sciences Journal. Volume 27, Issue 13, 2013, pp. 87-91.

Gabdrakhmanov N.K. and Rozhko M.V. Positioning of Volga Federal District Regions by Demographic Situation Index // World Applied Sciences Journal, Volume 30 Number 6, 2014. - pp.792-795

Gabdrakhmanov N.K. Social and economic premises for family formation in the Republic of Tatarstan // The Family in the Modern World: Materials of international scientific conference. - Helsinki; University of Helsinki, 2011 - pp.80-85.

Gabdrakhmanov Niyaz, and Egorov Dmitriy Report «The role of geo-demographic infrastructure facilities in the regional development of human capital» // WARSAW REGIONAL FORUM 2013 Territorial capital - concepts, indicators and policy by the Institute of Geography and Spatial Organization Polish Academy of Sciences, together with the Ministry of Regional Development of the Republic of Poland and Polish Geographical Society, Warsaw, p. 57

Guyatt, Gordon H., David H. Feeny, and Donald L. Patrick. "Measuring health-related quality of life." Annals of internal medicine 118.8 (1993): pp.622-629

Jitapunkul, Sutthichai, et al. "Disability-free life expectancy of elderly people in a population undergoing demographic and epidemiologic transition." Age and ageing 32.4 (2003): pp.401-405.

Mathers, Colin D., et al. "Global patterns of healthy life expectancy for older women." Journal of women \& aging 14.1-2 (2002): pp.99117. 
Mathers, Colin D., et al. "Healthy life expectancy in 191 countries, 1999." The Lancet 357.9269 (2001): pp.1685-1691

Nussbaum, Martha, and Amartya Sen. The quality of life. Oxford University Press, 1993

Panasyuk, M.V., Dzasaeva, R.D., Shaidullin, R.N., Anopchenko, T.Y. Problems of modernization of the health economics in the russian regions // World Applied Sciences Journal, 27(13), 2013, pp.154-158.

Perenboom, R. J. M., Van Herten, L. M., Boshuizen, H. C., \& Van Den Bos, G. A. M. (2004). Trends in disability-free life expectancy. Disability \& Rehabilitation, 26(7), pp.377-386

Robine, Jean Marie, and Karen Ritchie. "Healthy life expectancy: evaluation of global indicator of change in population health." BMJ: British Medical Journal 302.6774 (1991): 457 p.

Safiullin M.R., Elshin L.A., Shakirova A.I., Ermolaeva P.O., Prygunova M.I. (2013). Influence of Territorial Ecological Load Factors on Social and Economic Well-Being of Population: Methodology Development and Econometric Model Construction. World Applied Sciences Journal 25, 7, pp.1057-1061.

Sanders B. Measuring community health levels. // American journal of public health. - 1964. -Vol.54. - pp.1063-1070.

Sullivan D. A single index of mortality and morbidity. // HSMHA health report. - 1971. - Vol.86.- pp.347-354.

WHOQOL group. "The World Health Organization quality of life assessment (WHOQOL): position paper from the World Health Organization." Social science \& medicine 41.10 (1995): pp.1403-1409. 